\title{
Intermittent fasting combined with resistance training: effects on body composition, muscular performance, and dietary intake
}

\author{
Grant M Tinsley*, Natalie K Butler, Jeffrey S Forsse, Annie A Bane, Grant B Morgan, Paul S Hwang, \\ Peter W Grandjean, Paul M La Bounty \\ From The Twelfth International Society of Sports Nutrition (ISSN) Conference and Expo \\ Austin, TX, USA. 11-13 June 2015
}

\section{Background}

Intermittent fasting (IF) is a dietary strategy that has recently gained popularity due to a number of potential health benefits. One form of IF, termed time-restricted feeding (TRF), only allows caloric intake during a limited window of time each day (often 4 to 8 hours in duration). One concern of IF is the potential loss of lean mass due to the fasting periods. Resistance training is known to help mitigate loss of lean mass during hypocaloric diets. The purpose of this experiment was to examine the effects of TRF in combination with resistance training on body composition, muscular performance, and dietary intake in young untrained males.

\section{Methods}

Adult males $(\mathrm{n}=18)$ were recruited and randomized into one of two groups: resistance training alone (RT) or resistance training plus TRF (RT+TRF). Both groups followed a 3-days-per-week resistance training program for 8 weeks. The TRF program was implemented on nonworkout days (i.e. 4 days per week) and consisted of consuming all calories within any 4-hour period between 4 PM and midnight. Both groups were allowed unrestricted food intake during feeding periods. Research visits were conducted at baseline, 4 weeks, and 8 weeks after beginning the study and consisted of body composition assessment via dual-energy $x$-ray absorptiometry (DXA), 1-repetition maximum (1-RM) strength testing and muscular endurance testing on bench press and leg press exercises, and subjective measures of program difficulty. Diet records, workout logs, and compliance forms were used to

\footnotetext{
* Correspondence: Grant_Tinsley@baylor.edu
} Baylor University, Waco, TX, USA

\section{Conclusions}

In the absence of any other dietary guidance, restricting caloric consumption to a 4-hour window on 4 days per week was not sufficient to elicit body composition improvements in 8 weeks, although lean mass was maintained in both groups. This form of IF was sufficient to reduce caloric intake on fasting days, but this did not translate to body fat reductions in many subjects. Untrained young men experience similar strength adaptations whether they eat normally or perform this form of 
IF. Protein intake may be of particular concern for individuals implementing IF and young men beginning a resistance training program.

Published: 21 September 2015

doi:10.1186/1550-2783-12-S1-P38

Cite this article as: Tinsley et al:: Intermittent fasting combined with resistance training: effects on body composition, muscular performance, and dietary intake. Journal of the International Society of Sports Nutrition 2015 12(Suppl 1):P38

Submit your next manuscript to BioMed Central and take full advantage of:

- Convenient online submission

- Thorough peer review

- No space constraints or color figure charges

- Immediate publication on acceptance

- Inclusion in PubMed, CAS, Scopus and Google Scholar

- Research which is freely available for redistribution 